\title{
Pregnancy and the eye. Changes in morphology of the cornea and the anterior chamber of the eye in pregnant woman
}

\author{
Karol Taradaj ${ }^{1}$, Tomasz Ginda ${ }^{1}$, Piotr Maciejewicz' ${ }^{1}$, Piotr Ciechanowicz², Barbara Suchonska ${ }^{3}$, \\ Marta Hajbos ${ }^{3}$, Bozena Kociszewska-Najman ${ }^{4}$, Mirosław Wielgos ${ }^{3}$, Dariusz Kecik ${ }^{1}$ \\ ${ }^{1}$ Chair and Department of Ophthalmology, 1st Faculty of Medicine, Medical University of Warsaw, Poland \\ ${ }^{2}$ Department of Dermatology, Medical University of Warsaw, Poland \\ ${ }^{3} 7^{\text {st }}$ Chair and Department of Obstetrics and Gynecology, Medical University of Warsaw, Poland \\ ${ }^{4}$ Department of Neonatology, Medical University of Warsaw, Warsaw, Poland
}

\begin{abstract}
Objectives: The main goal of the study was to determine whether uncomplicated pregnancy and natural labor exert influence on the cornea and the anterior chamber of the eye.

Material and methods: The study included 114 eyes of 57 women in age of 21-35 years old. Only patients in the physiological pregnancy and giving natural birth were recruited into study.

Prospective observative examination was performed. Patients were diagnosed twice: in 36 HBD and 6 weeks after labor. Using the Scheimpflug camera (Pentacam system) the following parameters were assessed: central corneal thickness (CCT), keratometric parameters: flat (K1) and steep (K2), astigmatism value and axis, anterior chamber depth (ACD), anterior chamber volume (ACV) and anterior chamber angle (ACA). The statistical analysis was carried out in the StatSoft Statistica 13 program.

Results: CCT value is greater in the third trimester than in 6th week after the labour. ACD and ACA values are higher in $36 \mathrm{HBD}$ than in the post-partum period but the difference is not statistically important ( $p>0.05)$. K1, K2, cylindrical refraction error, axis of cylindrical refraction error do not change.

Conclusions: Authors claim that it is the result from an increase in water retention in the corneal stroma as a response to hormonal changes. The plasticity of the anterior chamber seen before delivery can be a natural adaptive mechanism of the female body, which counteracts the excessive increase in intraocular pressure in the second stage of delivery.

Key words: pregancy; cornea; anterior chamber of the eye; parturition; keratometry
\end{abstract}

Ginekologia Polska 2018; 89, 12: 695-699

\section{INTRODUCTION}

Pregnancy is a special physiological state of a woman's body, which is characterized by the variety of changes in many systems and organs. This fact inspired us to analyse the problem not only from the point of view of a gynecologist-obstetrician, but also in an interdisciplinary manner by specialists in other fields of medicine.

From the point of view of an ophthalmologist, it is essential to assess the impact of pregnancy and delivery on the eye. Therefore, it is necessary to establish if pregnancy modifies the anatomical structure of the cornea and the an- terior chamber of the eye. Inspired by the systematic review [1], which has recently appeared in the journal, we would like to present the results of our own research in which we assessed the impact of an uncomplicated pregnancy and a natural delivery on the changes in the anatomy of the anterior segment of the eye.

The results of the studies that have been published so far [2-6] do not allow to draw conclusions and specify the type of changes occurring in the anterior segment of the eye during pregnancy and the postpartum period. The discrepancy between the different researchers' results raises 
doubt and implies the legitimacy of conducting further research on a larger, more representative group of patients. It should also be noted that this type of research has not been conducted on the European population so far. Thus, it has become an aim for us to conduct our own research.

\section{Objectives}

The main goal of the study was to determine whether the uncomplicated pregnancy and the natural labor exert influence on the cornea and the anterior chamber of the eye. The additional aim was to assess whether pregnancy implies the change in corneal astigmatism, which could be evaluated analyzing the value of the refractive error itself and its derivatives.

\section{MATERIAL AND METHODS}

\section{Study group and research project}

The study included 218 eyes of 109 patients who were recruited in the physiological pregnancy clinic of the First Chair and Clinic of Obstetrics and Gynecology of the Medical University of Warsaw. The patients who were interested in participating in the study and expressed their written consent were directed to the Ophthalmology Clinic where the imaging examination of the anterior segment of the eye using the Scheimpflug camera (Pentacam system) was performed. The analyzed parameters included: central corneal thickness (CCT), keratometric parameters: flat (K1) and steep (K2), astigmatism value and axis, anterior chamber depth (ACD), anterior chamber volume (ACV) and iridocorneal angle (ACA). The protocol of the prospective study involved performing procedures during two visits: in the 36th week of pregnancy and in the 6th week after delivery. Due to resignation from the postnatal study, 104 eyes of 52 patients were excluded from the project. Finally, the analyzed group consisted of 114 eyes (57 patients). The inclusion and exclusion criteria are listed in Table 1. The study was performed by two independent, experienced researchers (who performed over 500 tests).The result is the arithmetic mean of both measurements obtained in the statistical analysis. All the tests were carried out without the use of mydriasis and cycloplegia with the consent of the Bioethical Committee.

\section{Statistical analysis}

The statistical analysis was carried out in the StatSoft Statistica 13. The significance level $p=0.05$ was adopted. The normality of distributions was assessed by the Shapiro-Wilk test. Exceptionally, due to the limit value of $p=0.07$ in the Shapiro- Wilk test for ACV after delivery, the normality of the distribution was tested again with the Lilliefors test, obtaining a value of $p<0.15$, which resulted in rejection of the null hypothesis about the lack of

Table 1. Inclusion and exclusion criteria

\begin{tabular}{|c|c|}
\hline Inclusion criteria & Exclusion criteria \\
\hline $\begin{array}{l}\text { Informed consent for participation } \\
\text { in the study }\end{array}$ & $\begin{array}{l}\text { No Informed consent for } \\
\text { participation in the study }\end{array}$ \\
\hline Age 18-35 & 18 years $>$ Age $>35$ years \\
\hline $\begin{array}{l}\text { Physiological Birth or } \\
\text { caesarean section }\end{array}$ & Complications of pregnancy \\
\hline Single pregnancy & Multiple Pregnancy \\
\hline $\begin{array}{l}\text { Refractive error }-4.00 \text { to }+4.00 \mathrm{D} \\
\text { sph. }\end{array}$ & $\begin{array}{l}\text { Refractive error greater } \\
\text { than }-4.00 \text { and }+4.00 \mathrm{D} \text { sph. }\end{array}$ \\
\hline Good cooperation during research & $\begin{array}{l}\text { Lack of cooperation during } \\
\text { research }\end{array}$ \\
\hline No eye diseases & Active eye disease \\
\hline $\begin{array}{l}\text { no operations or ophthalmic } \\
\text { procedures, including refractive } \\
\text { surgery in history }\end{array}$ & $\begin{array}{l}\text { Condition after surgery or } \\
\text { ophthalmic surgery, including } \\
\text { refractive surgery }\end{array}$ \\
\hline Delivery after 36 HBD & Premature delivery $<36 \mathrm{HBD}$ \\
\hline$V=5 / 5$ sc. s. cc. (BCVA) & $\mathrm{V}<5 / 5 \mathrm{cc}$ \\
\hline $\mathrm{Sn}=\mathrm{D} .0 .5$ sc. s. cc. (BCVA) & $\mathrm{Sn}<\mathrm{D} .0 .5 \mathrm{cc}$. \\
\hline
\end{tabular}

Table 2. Mean values. standard deviations. differences and values of Student's t-test and Wilcoxon-sequence test with the Marascuilo and McSweeney continuity correction for CCT, K1, K2, cylindric refraction error, astigmatism axes, ACD, ACV, ACA

\begin{tabular}{|l|l|l|l|l|l|}
\hline Parameters & Value in $\mathbf{3 6}$ HBD & $\begin{array}{l}\text { Value } \mathbf{6} \text { weeks after } \\
\text { delivery }\end{array}$ & Difference & $\begin{array}{l}\text { p-value of } \\
\text { t-Student's test }\end{array}$ & $\begin{array}{l}\text { p-value of } \\
\text { t-Wilcoxon's test }\end{array}$ \\
\hline CCT & $565.04 \pm 36.49$ & $561.09 \pm 36.95$ & 3.951 & 0.004 & 0.001 \\
\hline ACD & $3.08 \pm 0.33$ & $3.06 \pm 0.35$ & 0.023 & 0.07 & 0.02 \\
\hline ACA & $37.71 \pm 5.90$ & $36.75 \pm 5.94$ & 0.959 & 0.031 & 0.04 \\
\hline ACV & $183.46 \pm 38.34$ & $181.93 \pm 36.51$ & 1.537 & 0.204 & 0.280 \\
\hline K1 & $43.34 \pm 1.24$ & $43.36 \pm 1.23$ & 0.025 & 0.737 & 0.12 \\
\hline K2 & $44.23 \pm 1.29$ & $44.22 \pm 1.34$ & 0.010 & 0.706 & 0.73 \\
\hline Cylindrical refraction error & $0.89 \pm 0.50$ & $0.93 \pm 0.54$ & $X$ & $X$ & 0.09 \\
\hline Axis of cylidrical refraction error & $91.90 \pm 75.77$ & $87.98 \pm 77.28$ & $X$ & $X$ & 0.73 \\
\hline
\end{tabular}

$\mathrm{CCT}$ - central corneal thickness; $\mathrm{K} 1$ and $\mathrm{K} 2$ - corneal curvatures (K1 - flat parameters, $\mathrm{K} 2$ - strip parameters); $\mathrm{ACD}$ - anterior chamber depth; $\mathrm{ACV}$ - anterior chamber volume; ACA — anterior chamber angle 


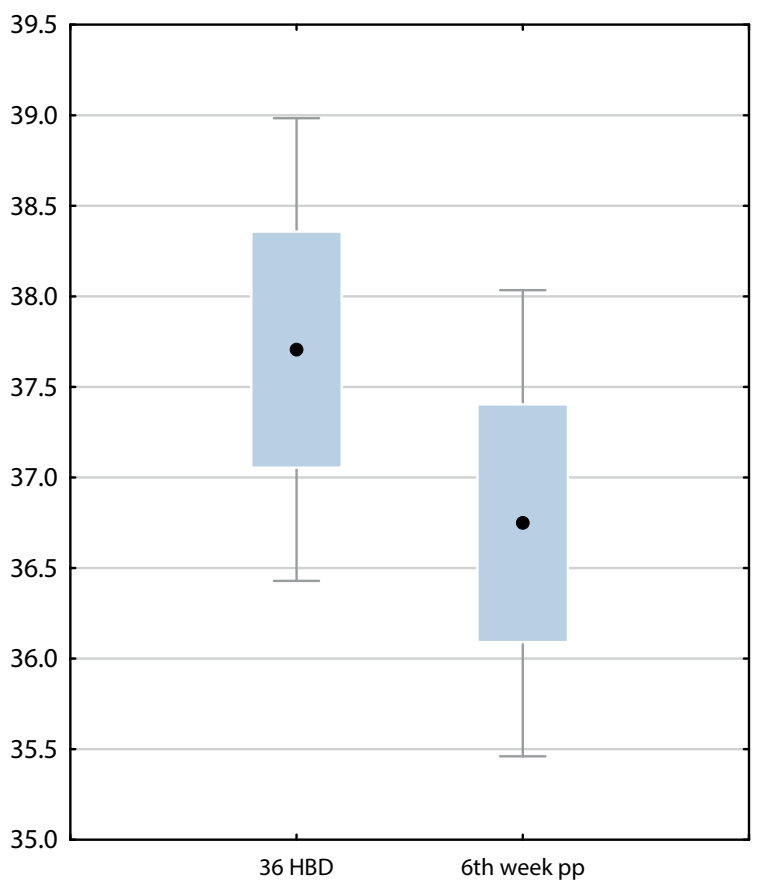

Figure 1. Anterior chamber angle (ACA)

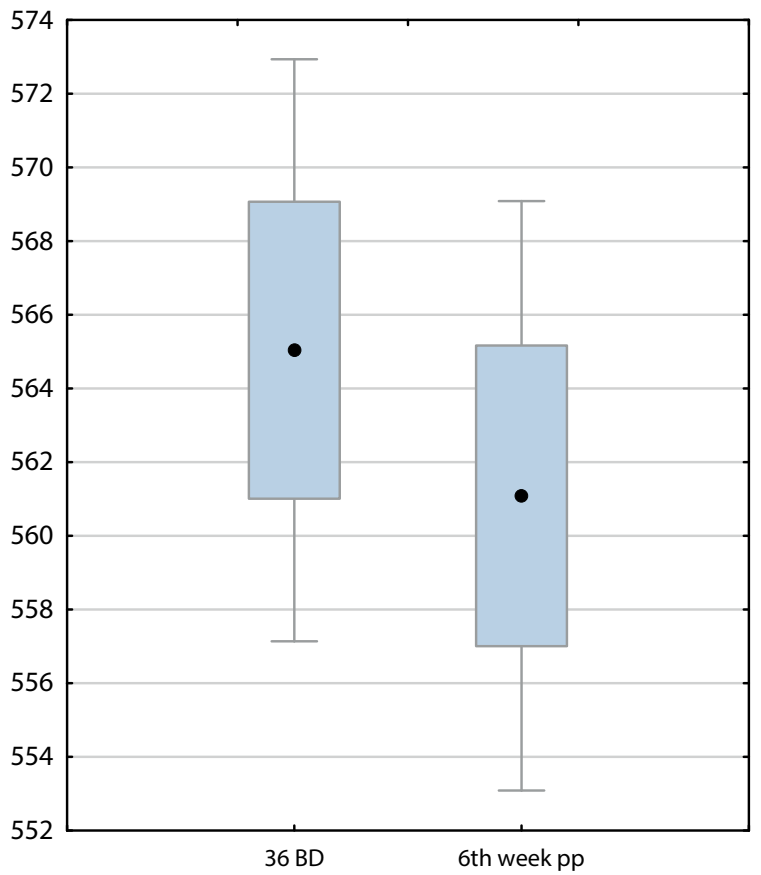

Figure 3. Central corneal thickness (CCT)

normality of distributions and admission of the variable to the test analysis parametric. The homogeneity of variance was evaluated using the Leavene's test. Student's t-tests for related trials and the Wilcoxon pairs order test with Marascuilo and McSweeney continuity correction were used to assess the significance of differences.

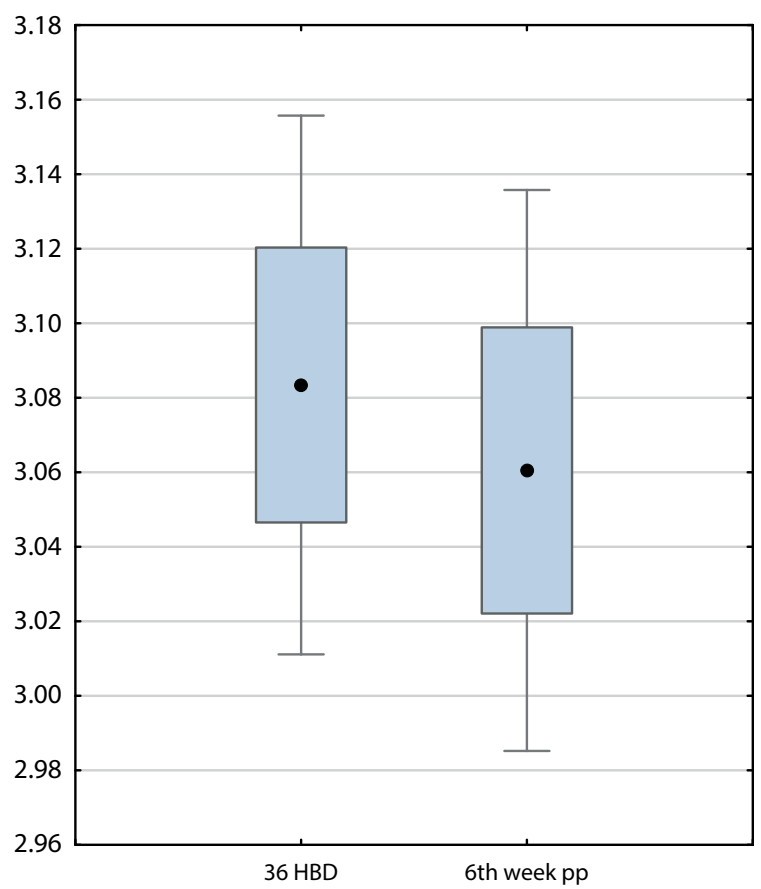

Figure 2. Anterior chamber depth (ACD)

\section{RESULTS}

The average age of the surveyed women was $28.25 \pm 5.55$ years (the age range of $18-35$ years). Table 2 presents mean values and standard deviations of the analyzed parameters: CCT, K1, K2, cylindric refraction defects, astigmatism axes, ACD, ACV, ACA. The results were compared, respectively, for the tests performed in HBD 36 and in the sixth week after delivery. The bolded font was used for the parameters with statistically significant differences. Statistically significant were differences in the pregnancy and the postpartum for parameters that meet the conditions for the rejection of the null hypothesis with no mean differences in the student's t-test and the equality of the sum of negative and positive rank for the Wilcoxon test with the significance level $a=0.05$.

The graphs (Fig. 1-3) illustrate the statistical differences based on the Student's t-test and the Wilcoxon pairs order test with the Marascuilo and McSweeney continuity correction for $C C T, A C D, A C A$ before and after delivery. The statistically significant differences were not shown for K1, $\mathrm{K} 2$, cylindric refractive error, astigmatism axis and $\mathrm{ACV}$.

\section{DISCUSSION}

The physiology of pregnancy is one of the most fascinating topics in medicine. Until now, despite numerous studies, all mechanisms that induce changes in part of the tissues and organs during pregnancy have not been precisely determined. It is known, however, that they are the result of changes in hormonal, immunological, hemodynamic and 
water-electrolyte regulation. In contrast to the numerous studies, describing in detail the impact of pregnancy on most organs, the visual system remains unavoidable in this area, which makes it a scientific challenge for researchers.

Our research team has attempted to explain the impact of the uncomplicated pregnancy and physiological labor on the morphology of the corneal microstructure and the anterior segment of the eye. Contrary to the studies of other authors, our analysis included the largest group of the examined patients so far (114 eyes 57 women).

The statistical analysis performed using the two-test method (Student's t-test and Wilcoxon-sequence test with Marascuilo and McSweeney continuity correction) showed that the central corneal thickness is higher in the third trimester of pregnancy ( $36 \mathrm{HBD}$ ) compared to the values in the early postnatal period ( 6 week postpartum). Differences were statistically significant $\left(p_{t-S t u d e n t ' s}=0.004, p_{\text {Wilcoxon's }}=0.001\right)$. The obtained results confirmed the observation of Atas et al. [3], who, on a group of 54 women of Turkish nationality, showed the increase in CCT in the third trimester in comparison to a study carried out after childbirth $(p<0.001)$. Our results, however, stand in opposition to the study of Sen et al. [6], Goldich et al. [5] and Naderan et al. [4] who, according to the systematic review by Taradaj et al. [1], did not show such the dependence. The precise mechanism that can explain the rise in CCT during pregnancy has not been described so far. Perhaps, however, the processes underlying it are related to the hormonal levels. Wickham et al. [7, 8] in his on vitro experiments showed the presence of mRNA for estrogen, progesterone and androgen receptors in the cornea and other ocular tissues in human and animal material. Considering that the maximum estrogen concentration occurs in the third trimester of pregnancy, estrogens, acting through corneal receptors detected by Wickham et al. [7, 8], may cause water retention in corneal stromal cells, which may be the direct cause of CCT increase in this period of pregnancy. The significant decrease in the value of this parameter in the postnatal period can be explained by the decrease in the concentration of gonadal steroids and the lack of retention effects of estrogens through receptors in the cornea on the tissues of the substantiae.

Our studies showed no relationship of pregnancy with $\mathrm{K} 1, \mathrm{~K} 2$, cylindrical refractive error and the axis of astigmatism. These results were confirmed by Naderan et al. However, they are not consistent with the results of other authors. Atas et al. [3] showed statistically significant differences in $\mathrm{K} 1$ and $\mathrm{K} 2$ values during pregnancy and after delivery. Goldich et al. [5] in their work described the increase in K2 only in the third trimester. The lack of influence of pregnancy on the determinants of astigmatism seems to be consistent with physiology and the clinic. In practice, there is no increase in the number of diagnoses or the build-up of existing deficiencies during pregnancy. In addition, there is no physiological basis for the increase of cylindric refraction error in pregnant women, in contrast to the spherical defect, which in the case of high myopia has a high impact on functional vision. High degree myopia with degenerative changes in the retina is an indication for caesarian section $[9,10]$.

An interesting increase in the biometric parameters of the anterior eye chamber (ACD and ACA) in the third trimester of pregnancy has been demonstrated. In addition to our work, these parameters were analyzed in pregnant women only by one team [3]. who showed the statistically significant increase in all three biometric variables of the anterior chamber in the third trimester of pregnancy (pACD $<0.001$, pACA $=0.002$, pACV $<0.001$ ). The results of our work deviated from the studies [3] only in relation to ACV (pACV $=0.204)$, for which we did not find statistically significant differences in pregnancy and postpartum. The mechanism responsible for the plasticity of the anterior chamber during pregnancy has not been explained yet, but pointing to the study by Keratepe et al. [11] who correlated these parameters with the menstrual cycle phase, showing a statistically significant increase in ACD on day 26 of the cycle in relation to the first day, it can be assumed that the regulation of hormone management is the reason for this variability. It is possible that estrogens that increase water retention by acting through the receptors present in the cornea play a role in this process, as in the case of CCT. The iridocorneal angle (ACA) - complex anatomical structure is the outflow site of $90 \%$ aqueous humor from the eyeball to the epidural veins through the Schlemm canal and trabeculum [12]. It is an essential regulator of eye hydrodynamics and intraocular pressure. The narrowing of ACA is the cause of ocular hypertension and closed angle glaucoma. The study showed the increase in ACA before childbirth.

\section{CONCLUSIONS}

1. The morphology of the cornea and the anterior chamber in the third trimester of pregnancy changes compared to the post-partum period.

2. The thickness of the central part of the cornea in the third trimester of pregnancy increases compared to the early postnatal period.

3. The defect of cylindrical refraction and its determinants in pregnancy do not change.

4. The plasticity of the anterior chamber seen before delivery can be a natural adaptive mechanism of the female body, which counteracts the excessive increase in intraocular pressure in the second stage of delivery.

\section{REFERENCES}

1. Taradaj K, Ginda T, Ciechanowicz $\mathrm{P}$, et al. Changes in the parameters of the anterior segment of the eye in pregnant women - literature review. Ginekologia Polska. 2018; 89(3): 169-173, doi: 10.5603/gp.a2018.0028. 
2. Efe $Y$, Ugurbas S, Alpay A, et al. The course of corneal and intraocular pressure changes during pregnancy. Canadian Journal of Ophthalmology. 2012; 47(2): 150-154, doi: 10.1016/j. jcjo.2012.01.004.

3. Ataş M, Duru N, Ulusoy D, et al. Evaluation of anterior segment parameters during and after pregnancy. Contact Lens and Anterior Eye. 2014; 37(6): 447-450, doi: 10.1016/j.clae.2014.07.013.

4. Naderan M, Jahanrad A. Anterior, posterior and biomechanical parameters of cornea during pregnancy in healthy eyes: a cohort study. British Journal of Ophthalmology. 2017; 102(3): 309-312, doi: 10.1136/bjophthalmol-2017-310247.

5. Goldich Y, Cooper M, Barkana Y, et al. Ocular anterior segment changes in pregnancy. Journal of Cataract \& Refractive Surgery. 2014; 40(11): 1868-1871, doi: 10.1016/j.jcrs.2014.02.042.

6. Sen E, Onaran Y, Nalcacioglu-Yuksekkaya P, et al. Corneal Biomechanical Parameters during Pregnancy. European Journal of Ophthalmology. 2018; 24(3): 314-319, doi: 10.5301/ejo.5000378.
7. Wickham LA, Rocha EM, Gao J, et al. Identification and hormonal control of sex steroid receptors in the eye. Adv Exp Med Biol. 1998; 438: 95-100, indexed in Pubmed: 9634870.

8. Wickham LA, Gao J, Toda I, et al. Identification of androgen, estrogen and progesterone receptor mRNAs in the eye. Acta Ophthalmol Scand. 2000; 78(2): 146-153, indexed in Pubmed: 10794246.

9. Karska-Basta I,TarasiewiczM, Kubicka-Trząska A, et al. Cesarean section and eye disorders. Polish Gynaecology.2016;87(03):217-221, doi:10.17772/gp/61752.

10. Socha MW, Piotrowiak I, Jagielska I. Retrospective analysis of ocular disorders and frequency of cesarean sections for ocular indications in 2000-2008--our own experience. , indexed in Pubmed: 20486539.

11. Karatepe AS, Onay MP, Eğrilmez S, et al. Menstrüel Siklusun Ön Kamara Parametreleri Üzerine Etkisinin Pentacam ile Araştırılması. Türk Oftalmoloji Dergisi. 2014; 44(1): 15-18, doi: 10.4274/tjo.43.97759.

12. Swaminathan SS, Oh DJ, Kang MH, et al. Aqueous outflow: segmental and distal flow. J Cataract Refract Surg. 2014; 40(8): 1263-1272, doi: 10.1016/j.jcrs.2014.06.020, indexed in Pubmed: 25088623. 